J. Electroanal. Chem., 313 (1991) 291-301

Elsevier Sequoia S.A., Lausanne

JEC 01552

\title{
Electrochemical study of hydrogen absorption in polycrystalline palladium
}

\author{
R.C. Salvarezza *, M.C. Montemayor and E. Fatas \\ Dpt. of Physical Chemistry, Universidad Autonoma de Madrid, 28049-Madrid (Spain)
}

A.J. Arvia

INIFTA, Universidad Nacional de La Plata, Sucursal 4, C. Correo 16, La Plata 1900 (Argentina)

(Received 4 January 1991; in revised form 5 February 1991)

\begin{abstract}
The hydrogen reactions on polycrystalline $\mathrm{Pd}$ in $0.1 \mathrm{M} \mathrm{NaOH}$ at $25^{\circ} \mathrm{C}$ have been studied by using transients at constant potential, and hy impedance spectroscopy and $\mathrm{X}$-ray diffraction techniques. At potentials, $E_{\mathrm{s}}$, more positive than the reversible potential, $E_{\mathrm{r}}$, for the $\mathrm{H}_{2}$ evolution reaction, the current-time response and the impedance data indicate $\mathrm{H}$ atom diffusion into the bulk Pd. The X-ray diffraction pattern of electrodes cathodized during $20 \mathrm{~min}$ at these potentials are similar to those obtained for Pd. At $E_{\mathrm{s}}<E_{\mathrm{r}}$, the current transients exhibit a current maximum which increases as $E_{\mathrm{s}}$ moves in the negative direction. The Nyquist plot for the rising part of the transients indicates the $\mathrm{H}$ atom diffusion into the bulk metal and $\mathrm{H}_{2}$ evolution on the Pd surface at high frequencies. The X-ray diffraction pattern of the electrodes cathodized at $E_{\mathrm{s}}<E_{\mathrm{r}}$ shows the presence of the $\beta \mathrm{PdH}$ phase and $\mathrm{Pd}$. The experimental results indicate that different reactions take place simultaneously in this potential range: (i) $\mathrm{H}_{2}$ evolution, (ii) $\mathrm{H}$ diffusion into the bulk $\mathrm{Pd}$, (iii) nucleation and diffusion-controlled growth of the $\beta \mathrm{PdH}$ phase. Taking into account the contribution of these reactions, a model, which is able to reproduce the experimental current transients, is presented.
\end{abstract}

\section{INTRODUCTION}

The cold fusion debate makes the electrochemistry of palladium and palladiumhydrogen systems attractive for further basic investigations, particularly those concerning the rate of hydrogen atom charging and the influence of inhibiting layers at the palladium surface.

The kinetics of hydrogen evolution and hydrogen adsorption on palladium have been studied for a few decades [1-5]. The discharge of hydrogen atoms yielding adsorbed hydrogen atoms is rather slow and it can be enhanced by increasing the

ॠ On leave from INIFTA, Universidad Nacional de La Plata, Argentina. 
applied cathodic overpotential. On the other hand, the absorption of hydrogen involves a transport process into the bulk of the metal, the rate of which can be increased by providing a greater concentration of hydrogen atoms at the metal surface. This can be done also by increasing the applied cathodic overpotential to reach the saturation of the hydrogen surface concentration. For a certain electrolysis time the $\mathrm{H}$-adsorption process is coupled to the parallel evolution of molecular hydrogen until the limiting uptake of hydrogen is reached [6]. Afterwards, the hydrogen evolution reaction proceeds under steady conditions on an electrode composed of the $\beta \mathrm{PdH}$ phase.

The purpose of the present work was to study of the early stages of cathodization of a palladium electrode in a base electrolyte. A kinetic analysis of the various processes occurring during the formation of the $\alpha \mathrm{PdH}$ and $\beta \mathrm{PdH}$ phases is presented. The results from potentiostatic current-time transients, impedance measurements and X-ray diffractometry show that nucleation and growth models seem to be applicable to the phase changes involved in these reactions.

\section{EXPERIMENTAL}

Polycrystalline Pd (99.99\%) wires (dia. $0.05 \mathrm{~cm}$, ca $0.1 \mathrm{~cm}^{2}$ area), polished with alumina ( $1 \mu \mathrm{m}$ dia.) and cleaned by immersion in $\mathrm{HNO}_{3}+\mathrm{H}_{2} \mathrm{SO}_{4}$ mixture $(1: 1)$ at $70^{\circ} \mathrm{C}$ were used as working electrodes. The latter, a large $\mathrm{Pt}\left(3 \times 3 \mathrm{~cm}^{2}\right)$ counter electrode and a $\mathrm{Hg} / \mathrm{Hg}_{2} \mathrm{SO}_{4}$ reference electrode were placed in a conventional electrochemical glass cell thermostated at $25^{\circ} \mathrm{C}$. The electrolyte solution was $0.1 \mathrm{M}$ $\mathrm{LiOH}$ prepared from p.a. chemicals and bi-distilled water. Oxygen was removed from the cell solution by passing $\mathrm{N}_{2}$ through it. Prior to the electrochemical measurements, the working electrode was cycled between $0.05 \mathrm{~V}$ and $-1.1 \mathrm{~V}$ at 0.05 $\mathrm{V} / \mathrm{s}$ in order to obtain stabilized voltammograms.

Voltammetric measurements combined with potentiostatic current-time transients and cell impedance measurements were made. The latter were obtained using a frequency response analyzer (Solartron 1250), coupled with a potentiostat. In this case, a large cylindrical $\mathrm{Pt}$ grid was used as the counter electrode. The amplitude of the ac signal was $8 \mathrm{mV}$ peak-to-peak and the frequency range between $1 \mathrm{~Hz}$ and 10 $\mathrm{kHz}$. Six points per decade were measured. The completion of a frequency spectrum required about $30 \mathrm{~s}$. The analyzer was used in the two channel mode, one channel for the alternating current output of the potentiostat and the other for the corresponding alternating voltage output.

In order to detect the electroformation of the $\beta \mathrm{PdH}, \mathrm{Pd}$ electrodes cathodized at various potentials were removed from the electrochemical cell and analyzed immediately by X-ray diffraction in the Debye chamber of a Philips diffractometer with $\mathrm{Cu}-K_{\alpha}$ radiation. In this case, $\mathrm{Pd}$ plates $\left(1.5 \mathrm{~cm}^{2}\right)$ were used as working electrodes.

RESULTS

The voltammogram of a polycrystalline Pd electrode in $0.1 \mathrm{M} \mathrm{LiOH}$ run between $-1.25 \mathrm{~V}$ and $0.05 \mathrm{~V}$ at $0.05 \mathrm{~V} / \mathrm{s}$ (Fig. 1) exhibits a current peak at $-0.7 \mathrm{~V}$ in the 


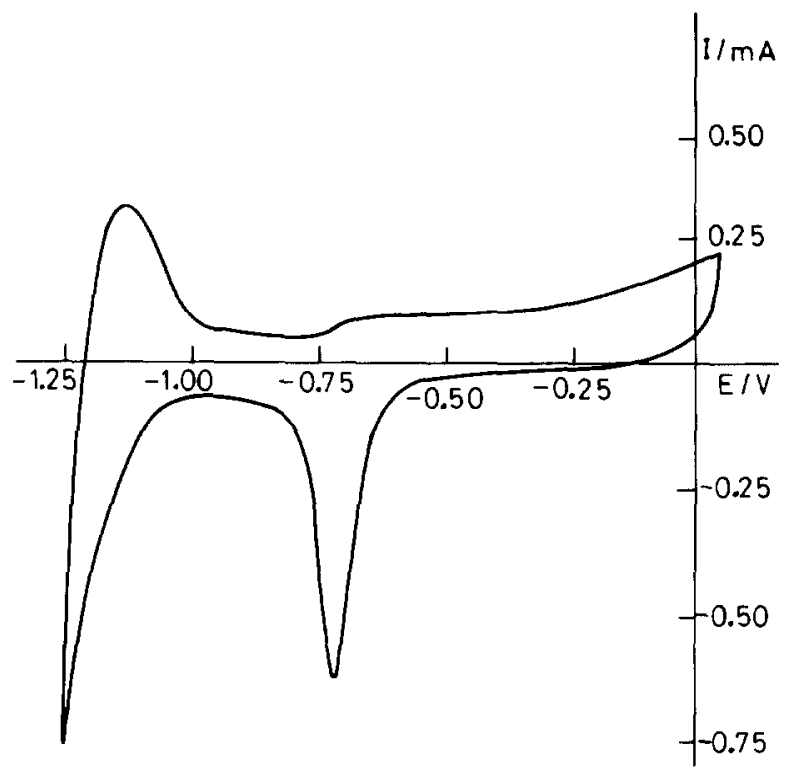

Fig. 1. Voltammetric current-potential curve obtained at $0.05 \mathrm{~V} \mathrm{~s}^{-1}$ for hydrogen deposition on palladium in $0.1 \mathrm{M} \mathrm{LiOH}$.

scan to negative potentials corresponding to the PdO electroreduction [5]. At potentials lying between $-1.0 \mathrm{~V}$ and $E_{\mathrm{r}}$, the reversible potential of the hydrogen electrode $\left(E_{\mathrm{r}}=-1.37 \mathrm{~V}\right), \mathrm{H}$ atom electroadsorption and the simultaneous formation of the $\alpha \mathrm{PdH}$ alloy takes place. Finally, at potentials more negative than $E_{\mathrm{r}}$ the large cathodic current is related to hydrogen evolution and $\beta \mathrm{PdH}$ alloy formation. The scan to positive potentials shows a broad current peak at $-1.1 \mathrm{~V}$ corresponding to $\mathrm{H}_{2}$ and $\mathrm{H}$ atom electrooxidation, the latter reaction extending over the double layer potential region. Finally for potentials more positive than $-0.7 \mathrm{~V}$ a broad current region associated with the PdO formation is observed.

The current transients, run under a constant potential $\left(E_{\mathrm{s}}\right)$, were recorded by stepping the electrode from a potential of $-1.1 \mathrm{~V}$ to $E_{\mathrm{s}}\left(-1.20 \mathrm{~V}>E_{\mathrm{s}}>-1.9 \mathrm{~V}\right)$. For $E_{\mathrm{s}}>-1.37 \mathrm{~V}$ and time covered in the present work, the current transient decays continuously (Fig. 2a), yielding linear $j$ vs. $t^{-1 / 2}$ plots. For $E_{\mathrm{s}}<-1.37 \mathrm{~V}$, the current decreases initially to a minimum value, $j_{\mathrm{m}}$, at time $t_{\mathrm{m}}$, and subsequently it increases to a maximum value, $j_{\mathrm{M}}$, at time $t_{\mathrm{M}}$ (Fig. 2b). Finally, the current decreases slowly with time. In addition, $t_{\mathrm{M}}$ decreases and $j_{\mathrm{M}}$ increases as $E_{\mathrm{s}}$ is shifted negatively. Peaked current transients were also observed during $\mathrm{H}_{2}$ evolution and hydride layer formation on $\mathrm{Ti}$ [8]. These transients were related to the time-dependent electroreduction of the oxidized species, i.e. $\mathrm{O}_{2}$, transported from the counter electrode to the $\mathrm{Ti}$ working electrode. However, in our case, the voltammograms run immediately after cathodization in the $-1.25 \mathrm{~V}$ to -1.90 range 

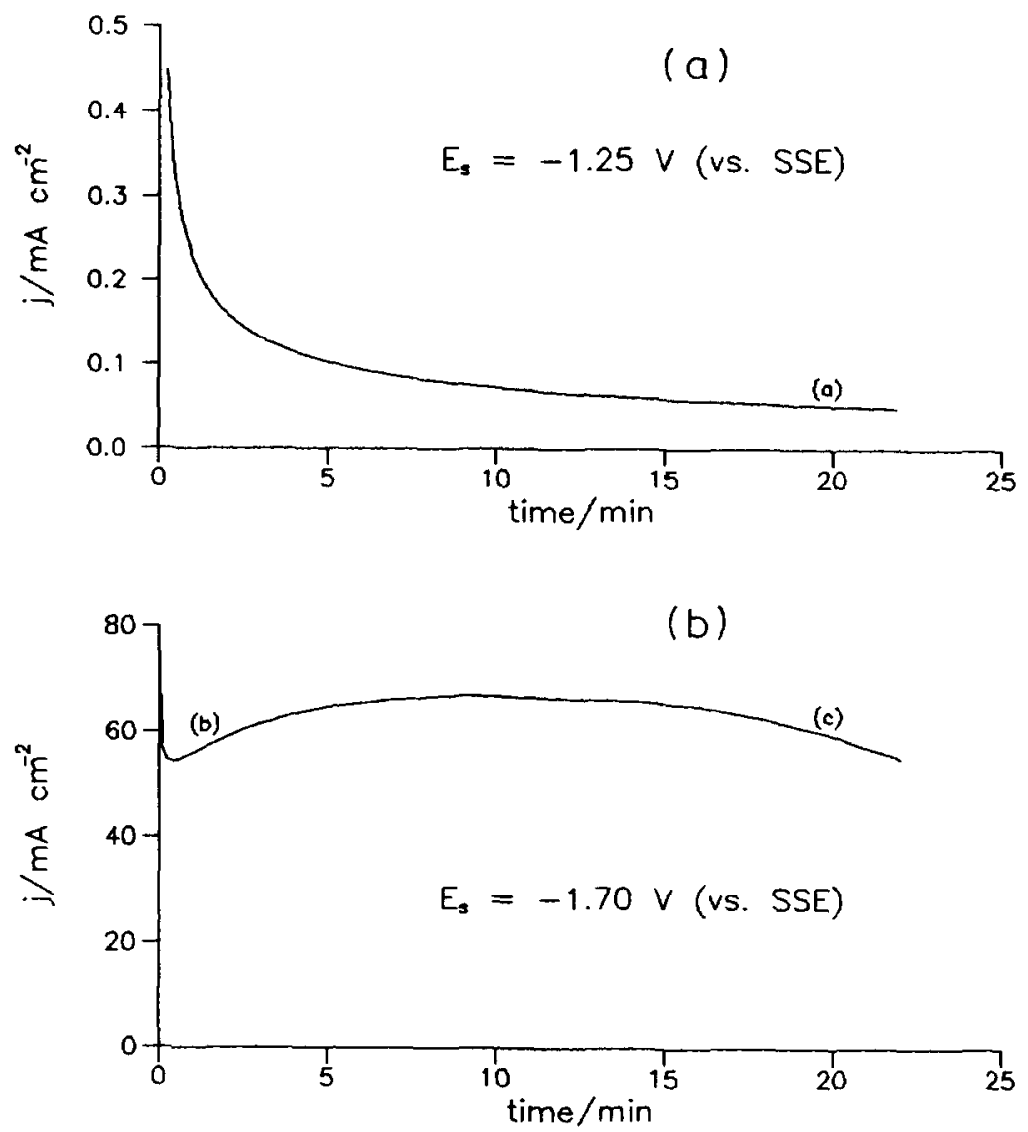

Fig. 2. Potentiostatic current transients of the hydrogen reaction on Pd.

reveal no significant traces of $\mathrm{O}_{2}$ which would cause a distortion in the shape of the voltammogram.

Impedance measurements were also made in the $-1.25 \mathrm{~V}>E_{\mathrm{s}}>-1.90 \mathrm{~V}$ range. For $E_{\mathrm{s}}=-1.25 \mathrm{~V}$, the Nyquist plot shows, at high frequencies $(\omega)$, the characteristic circular plot corresponding to a charge transfer controlled process. On the other hand, at low $\omega$ values, a straight line with slope close to unity, representing the Warburg impedance was found (Fig. 3a). For $E_{\mathrm{s}}=-1.70 \mathrm{~V}$, the Nyquist plot (Fig. $3 b)$ recorded in the rising part of the transient, at high $\omega$ values, shows the semicircle expected for a charge transfer controlled process, although it is perturbed by $\mathrm{H}_{2}$ bubble formation at the electrode. It should be noted that at sufficiently low values of $\omega$ there is a diffusional process. The latter is no longer observed for $t>t_{\mathrm{M}}$ but in this case an increase of the charge transfer resistance is observed (Fig. 3c). 

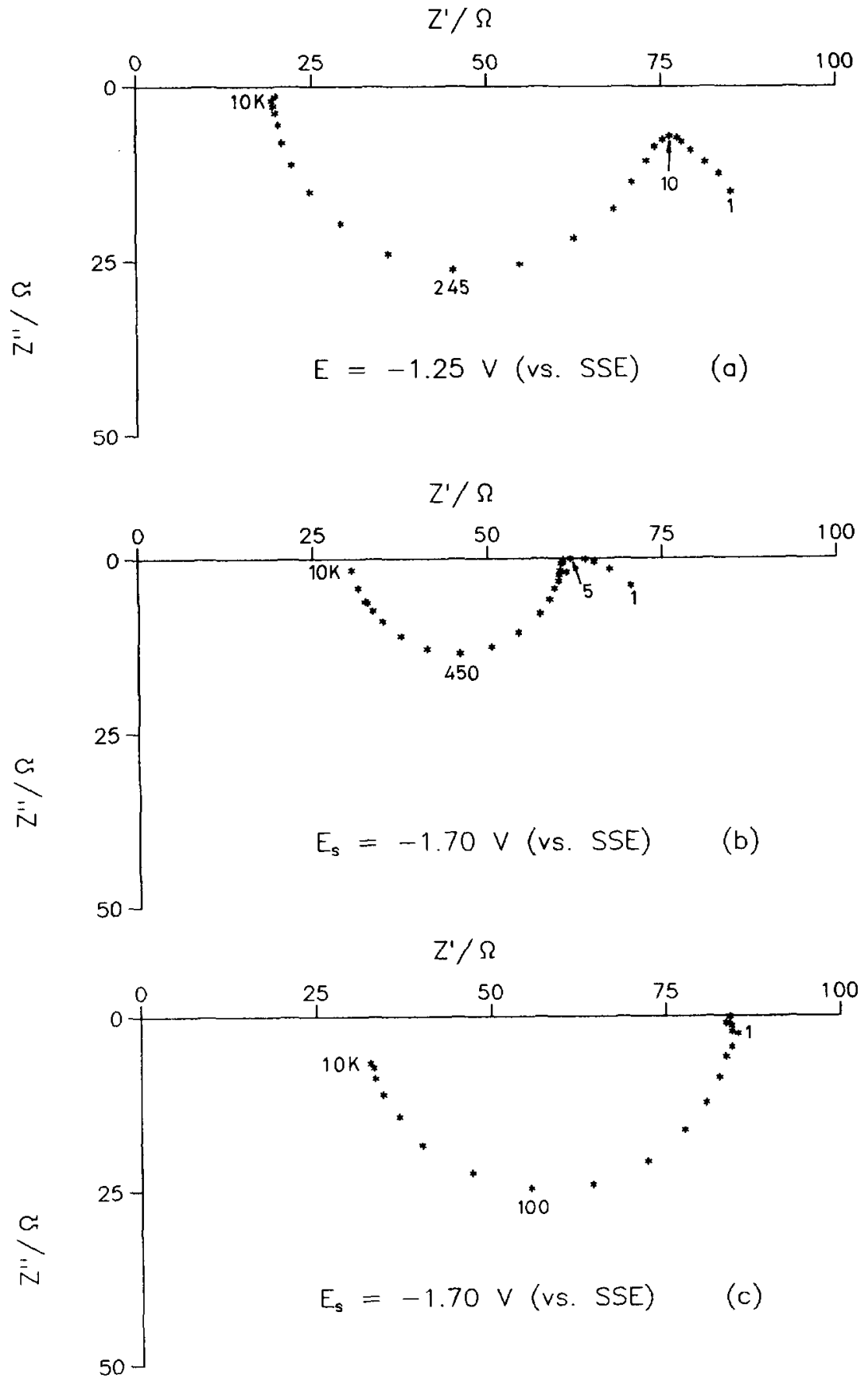

Fig. 3. Complex impedance plots for the hydrogen reaction on $\mathrm{Pd}$ at the potential indicated and times corresponding to points (a), (b) and (c) of Figs. $2 a$ and $2 b$ respectively. 

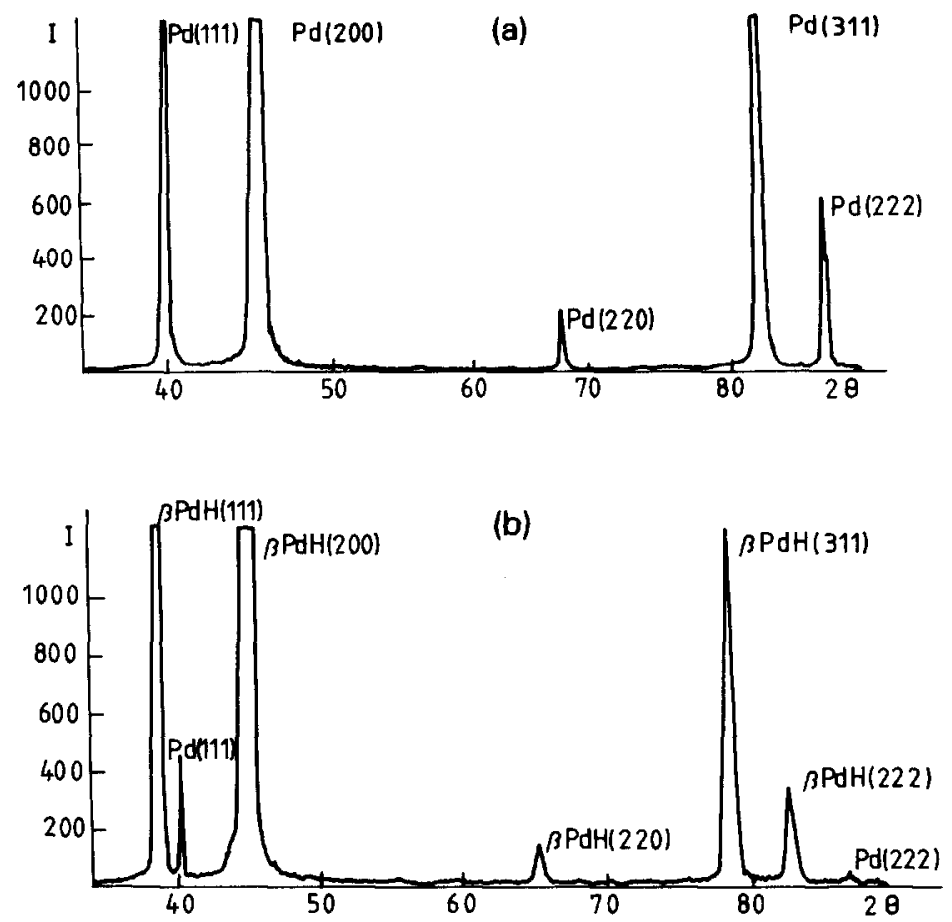

Fig. 4. X-ray diffraction patterns corresponding to (a) Pd cathodized at $-1.25 \mathrm{~V}$ during $20 \mathrm{~min}$. (b) $\mathrm{Pd}$ cathodized at $-1.70 \mathrm{~V}(\beta \mathrm{PdH})$.

In order to verify that peaks in the current transients are related to the growth of the $\beta \mathrm{PdH}$ phase, $\mathrm{X}$-ray diffractograms of the electrodes cathodized at various potentials $(20 \mathrm{~min})$ were made. For $E_{\mathrm{s}}=-1.25 \mathrm{~V}$, that is for decreasing current transients, the diffractograms coincide, as can be seen from Fig. 4a, with those obtained for untreated $\mathrm{Pd}$. Conversely, for $E_{\mathrm{s}}=-1.70 \mathrm{~V}$, where peaks in the current transients are observed, the diffractograms are closely related to those of $\beta$ PdH alloy with only a small signal from Pd (Fig. 4b).

\section{DISCUSSION}

The results obtained from the potentiostatic current transients combined with those from ac impedance measurements, indicate that several electrochemical processes are taking place in the potential range of the hydrogen electrode reactions. These processes can be considered separately by operating under certain defined potential and time windows. Thus, for $E_{\mathrm{s}}>-1.37 \mathrm{~V}$ the main reaction can be represented formally as the following successive steps [9]:

$\mathrm{H}_{2} \mathrm{O}+\left(\mathrm{Pd}_{x}-\mathrm{e}^{-}\right) \rightarrow(\mathrm{H}) \mathrm{Pd}_{x}+\mathrm{OH}^{-}$

$\mathrm{H}^{+}+\left(\mathrm{Pd}_{x}-\mathrm{e}^{-}\right) \rightarrow(\mathrm{H}) \mathrm{Pd}_{x}$

$(\mathrm{H}) \mathrm{Pd}_{x} \rightarrow \alpha\left(\mathrm{Pd}_{x} \mathrm{H}\right)$ 
TABLE 1

Parameter values of the proposed model at various potentials.

\begin{tabular}{lllcc}
\hline$E_{\mathrm{s}} / \mathrm{V}$ & $P_{1} / \mathrm{mA} \mathrm{cm}^{-2} \mathrm{~s}^{-1 / 2}$ & $10^{3} P_{2} / \mathrm{s}^{-1 / 2}$ & $P_{3} / \mathrm{mA} \mathrm{cm}^{-2}$ & $10^{4} P_{4} / \mathrm{s}^{-1}$ \\
\hline-1.25 & 1.74 & - & - & - \\
-1.55 & 29.0 & 8.3 & 7.1 & 12 \\
-1.65 & 32.9 & 1.0 & 29.6 & 2.0 \\
-1.70 & 21.3 & 15 & 49.37 & 4.3 \\
-1.80 & 36.7 & 37 & 67.2 & 15 \\
-1.90 & 34.8 & 33 & 119.8 & 6.6 \\
\hline
\end{tabular}

where $(\mathrm{H})$ stands for an adsorbed $\mathrm{H}$-atom on the $\mathrm{Pd}_{x}$ surface and $\alpha(\mathrm{HPd})_{x}$ ) refers to the $\alpha \mathrm{PdH}$ phase. Steps (1a) correspond to the $\mathrm{H}$-atom electroadsorption and step (2a) to the diffusion of $\mathrm{H}$-atom into the bulk Pd. The total current related to the $\alpha \mathrm{PdH}$ phase formation is

$j_{\mathrm{t}}=j_{1 \alpha}=j_{2 \alpha}$

where $j_{1 \alpha}$ and $j_{2 \alpha}$ are the current of steps (1a) and (2a), respectively. Voltammetric results in this potential range suggest that step (2a) is the rate determining step [9]. Furthermore, the linear $j$ vs. $t^{-1 / 2}$ relationship indicates that the hydrogen penetration into Pd can be described as a linear diffusion process. Thus, one can write [10]

$j_{\mathrm{t}}=P_{1} / t^{1 / 2}$

with

$P_{1}=z F D^{1 / 2} c_{\mathrm{H}}^{s} / \pi^{1 / 2}$

$D$ is the diffusion coefficient of $\mathrm{H}$ atoms into bulk $\mathrm{Pd}$ and $\mathrm{C}_{\mathrm{H}}^{\mathrm{s}}$ is the $\mathrm{H}$ atom concentration at the Pd surface. Using equation (4) the current transients recorded at $E_{\mathrm{s}}>-1.37 \mathrm{~V}$ can be reproduced with the set of parameters assembled in Table 1 , the error being less than $1 \%$. From the value of $P_{1}$ given by equation (5) and taking $z=1$, and $D=1 \times 10^{-7} \mathrm{~cm}^{2} \mathrm{~s}^{-1}$ [7] one obtains $c_{\mathrm{H}}^{\mathrm{s}}=1 \times 10^{-4} \mathrm{~mol} \mathrm{~cm} \mathrm{~cm}^{-3}$. Our impedance measurements in this potential range show (Fig. 3a) the appearance of a straight line in the low frequency zone which is interpreted as a Warburg impedance. In principle, this frequency range seems rather narrow to be unambiguously assigned to a Warburg impedance. However, lower frequency measurements are not convenient under non-steady state conditions as they involve larger times than those corresponding to the processes under study. Nevertheless, our results are in good agreement with the detailed impedance study of Breiter [9] on the hydrogen adsorption and dissolution on $\mathrm{Pd}$ in acidic medium. In this case, the experimental data are in favor of casc b (eqn. 14 of ref. 9) at sufficiently low frequencies, which corresponds to low values of an adsorption pseudocapacitance. Thus, it is possible to use a Warburg-like approach to describe the behaviour of the system. From the Warburg impedance, calculated from the low frequency region of Fig. 3a, and using the expression

$\sigma=\left(4 R T / z^{2} F^{2} 2^{1 / 2} c D\right) \cosh ^{2}[(z F / 2 R T)] \eta$ 
a value of $c_{\mathrm{H}}^{5}=0.9 \times 10^{-4} \mathrm{~mol} \mathrm{~cm}-9$ is obtained, which is in very good agreement with that obtained from $P_{1}$ data. It should be noted that $C_{\mathrm{H}}^{\mathrm{s}}$ is lower than that required for $\beta \mathrm{PdH}$ formation [11]. This conclusion is supported by the $\mathrm{X}$-ray diffractogram data showing no evidence for this phase in this potential range.

On the other hand, when $E_{\mathrm{s}}<-1.37 \mathrm{~V}$, the adsorbed $\mathrm{H}$ atom can react at least in three different ways to yield (i) $\mathrm{H}_{2}$ molecules, (ii) $\alpha \mathrm{PdH}$ phase, or (iii) $\beta \mathrm{PdH}$ phase. The entire process can be described by the following alternative reaction pathway:

$$
\begin{aligned}
& (\mathbf{H})\left(\mathbf{P d}_{x} \mathrm{e}^{-}\right)+\mathrm{H}^{+} \longrightarrow \mathrm{H}_{2}+\mathrm{Pd}_{x} \\
& \mathrm{H}^{+}+(\mathrm{H}) \mathrm{Pd}_{x} \longrightarrow \alpha\left(\mathrm{Pd}_{x} \mathrm{H}\right) \\
& \downarrow \\
& \beta\left(\operatorname{Pd}_{x} \mathrm{H}\right)
\end{aligned}
$$

As the reaction progresses, the electrode surface turns into a composite structure containing $\alpha\left(\operatorname{Pd}_{x} \mathrm{H}\right)$ and $\beta\left(\operatorname{Pd}_{x} \mathrm{H}\right)$ and Pd domains, the ratios of the domains depending on the extent of the corresponding reactions and applied potentials.

For the reaction scheme $(2 \mathrm{a}-2 \mathrm{c})$ the total instantaneous current $j_{1}$, is

$j_{1}=j_{2 \alpha}+j_{2 \mathrm{~b}}+j_{2 \mathrm{c}}$

where $j_{2 \alpha}$ is the current associated with the hydrogen evolution reaction, and $j_{2 b}$ and $j_{2 c}$ are the currents associated with the formation of the $\alpha \mathrm{PdH}$ and $\beta \mathrm{PdH}$ phases respectively.

The X-ray diffractograms reveal that the current transients with peaks are related to the electroformation of the $\beta \mathrm{PdH}$ phase. The shape of these current transients resembles that observed for the nucleation and growth of a new phase. Thus, let us assume that the formation of the $\beta \mathrm{PdH}$ phase can be represented by an instantaneous nucleation in a thin region of the Pd surface supersaturated in $\mathrm{H}$ atoms, followed by diffusion controlled growth of $N$ isolated 3D nuclei. It implies that the linear diffusion of the $\mathrm{H}$ atoms into the bulk Pd turns into hemispherical diffusion around the growing nuclei. Similar considerations are valid for hydrogen dissolved into the $\beta \mathrm{PdH}$ nuclei, which can also change from linear to hemispherical diffusion at the growing $\mathrm{Pd} / \beta \mathrm{PdH}$ interface [12]. Then the corresponding current transient run at a constant potential should obey the equation [13]

$j_{2 \mathrm{c}}=P_{2} t^{1 / 2}$

where

$P_{2}=z F \pi\left(2 D c_{\mathrm{H}}^{\mathrm{s}}\right)^{3 / 2} M^{1 / 2} N / \rho^{1 / 2}$

In equation (9) $M$ and $\rho$ are the molar mass and density, and $N$ is the number of growing nuclei of the $\beta \mathrm{PdH}$ phase.

On the other hand, the impedance data indicate that the $\mathrm{H}_{2}$ evolution on a composite $\mathrm{Pd} / \beta \mathrm{PdH} / \alpha \mathrm{PdH}$ electrode becomes more difficult than on the $\mathrm{Pd}$. 


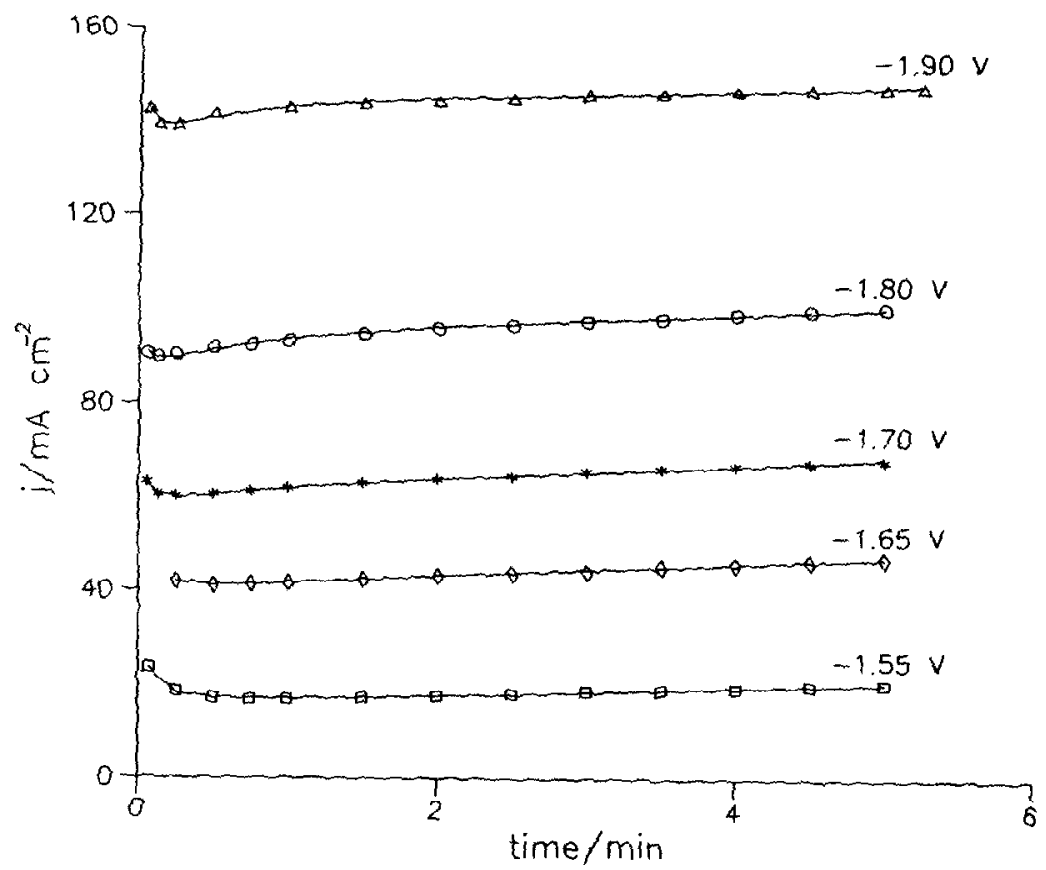

Fig. 5. Potentiostatic current transients at the indicated potentials. (Points) Experimental data. (Lines) Calculated with equation (5) and parameters of Table 1.

Therefore, one should expect that $\dot{j}_{2 \mathrm{~b}}$ becomes a function of the fraction of $\mathrm{Pd}$ converted into the $\beta \mathrm{PdH}$ at the electrode surface. Accordingly, the rate of hydrogen evolution should gradually decrease as the Pd surface is replaced by the growth of the $\beta P d H$ hemispherical nuclei. The intersection of the latter with the Pd surface generates circular growth centers. Thus, the fraction, $S$, of the Pd surface converted into the $\beta$ PdH phase can be estimated from [14]

$S=\pi K D N_{\mathrm{s}} t$

where $N_{\mathrm{s}}$ is the number of $\beta \mathrm{PdH}$ centers at the surface.

Thus, $j_{2 b}$ should be given by

$j_{2 b}=P_{3}\left[1-P_{4} l\right]+P_{5}(t)$

where $P_{3}$ is the $\mathrm{H}_{2}$ evolution current on an uncovered $P d(t \rightarrow 0), P_{4}=\pi X D N$ and $P_{5}(t)$ represents the hydrogen evolution on the $\beta P d H$ phase. Assuming that $P_{3}[1-$ $\left.P_{4} t\right] \gg P_{S}(t)$, for $t<300 \mathrm{~s}$, equation (11) becomes

$j_{2 \mathrm{~b}}=P_{3}\left[1-P_{4} t\right]$

By using equations (7) and (4), (8) and (12), the initial part of the current transients recorded at $E_{\mathrm{s}}<-1.4 \mathrm{~V}$ can be reproduced (Fig. 5) with parameters assembled in Table 1. 


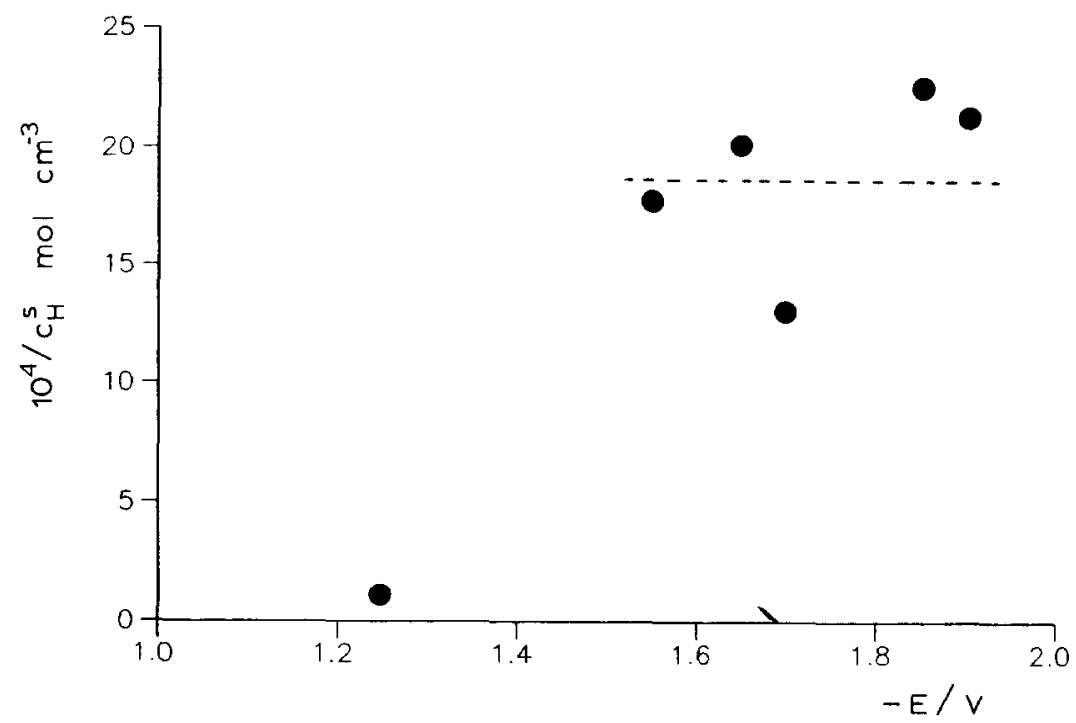

Fig. 6. Potential dependence of the $\mathrm{H}$ atoms concentration at the Pd surface.

The value of $P_{1}$ increases with with $E_{\mathrm{s}}$ to attain a limiting value which is close to $c_{\mathrm{H}}^{\mathrm{s}}=2 \times 10^{-3} \mathrm{~mol} \mathrm{~cm}{ }^{-3}$ for $E_{\mathrm{s}}<-1.37 \mathrm{~V}$ (Fig. 6). This value is similar to that reported as the critical concentration of $\mathrm{H}$ atoms required to form the $\beta \mathrm{PdH}$ phase [11]. This means that in a thin Pd layer close to the surface the $H$ supersaturation to form the nuclei of the $\beta \mathrm{PdH}$ is reached at more negative potentials than $-1.37 \mathrm{~V}$.

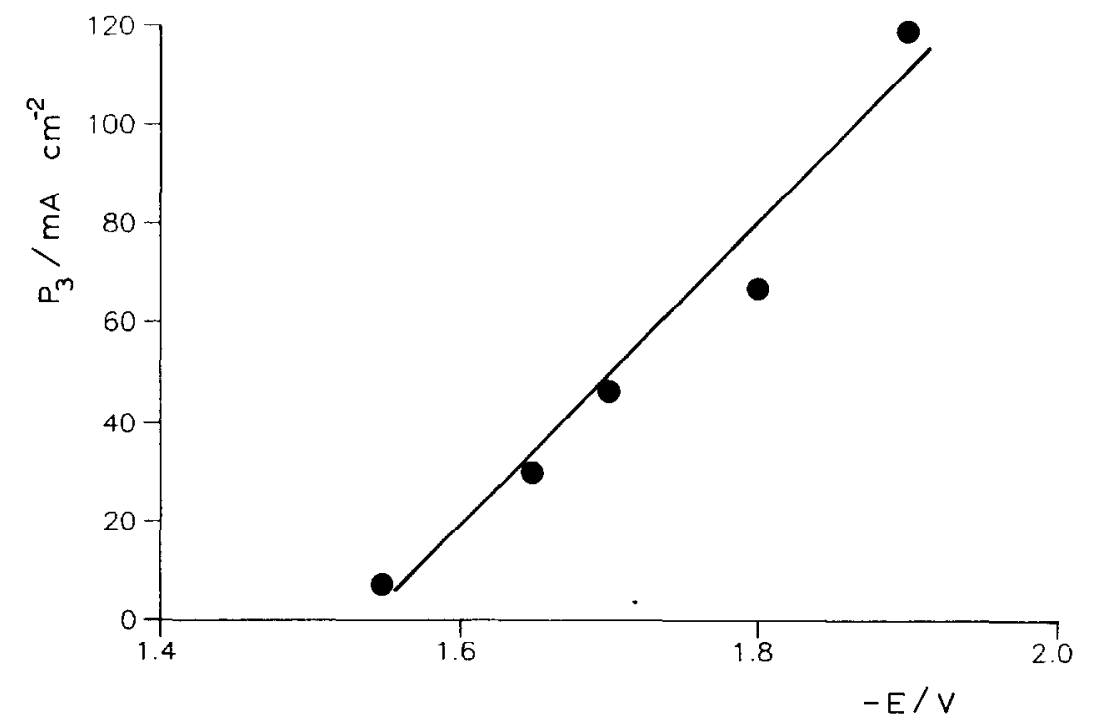

Fig. 7. Influence of the potential on the values of the parameter $P_{3}$ of equation (9). 
On the other hand, despite the scatter, $P_{2}$ and $P_{4}$ show no marked dependence on $E_{\mathrm{s}}$. This is consistent with the assumption of instantaneous nucleation with $N$ being independent of the $E_{\mathrm{s}}$ value and a diffusion-controlled growth. From equation (9) one can estimate $N$ close to $10^{8} \mathrm{~cm}^{-2}$. In addition, using equation (12) for $t=300 \mathrm{~s}$, values of $S$ are in the range $0.1-0.3$, that is, only a fraction of the $\mathrm{Pd} / \alpha \mathrm{PdH}$ surface is covered by the $\beta \mathrm{PdH}$ phase. This figure justifies a posteriori the assumption that $j_{2 \mathrm{~b}}$ is related mainly to hydrogen evolution on the Pd surface.

The potential dependence of $P_{3}$ gives information on the $\mathrm{H}_{2}$ evolution reaction on a Pd electrode at high negative potential. In this case, the $P_{3}$ vs. $E_{\mathrm{s}}$ plot (Fig. 7) corresponds to a straight line with a slope equal to $25 \Omega$ in good agreement with the impedance data $(20-30 \Omega)$. These data are consistent with an ohmic controlled process.

Finally, it should be noted that the validity of the overall approach is supported by the physical meaning of the adjustable parameters yielding reasonable figures about the kinetics of the various processes in this potential range.

However, the kinetic model according to equation (7) accounts for the initial part of the current transients i.e. for $t<t_{\mathrm{M}}$. Otherwise, for $t>t_{\mathrm{M}}$ the overlap of growing nuclei and the depletion of the Pd phase leads to more complex current transient behaviour which is difficult to reproduce using simple models.

\section{ACKNOWLEDGEMENTS}

Thanks are due to Professor C. Sanchez for encouragement to undertake this work and valuable discussions and B. Escarpizo for her assistance in part of the experimental measurements.

\section{REFERENCES}

1 K.J. Vetter, Electrochemical Kinetics. Academic, London, 1967.

2 J.O.'M. Bockris and P.K. Subramanyan, Electrochim. Acta, 16 (1971) 2169.

3 L.J. Krishtalik and V.M. Tsionsky, J. Electroanal. Chem., 31 (1971) 363.

4 J.P. Chevillot, J. Farcy, C. Hinnen and A. Rousseau, J. Electroanal. Chem., 64 (1975) 39.

5 M.W. Breiter, J. Electroanal. Chem., 81 (1977) 275.

6 B. Pfeiffer, A. Thyssen and J.N. Schulze, J. Electroanal. Chem., 260 (1989) 393.

7 F.A. Lewis, The Hydrogen Palladium System, Academic, London, 1967.

8 W. Wilhelmsen and A. Peder Grande, Electrochim. Acta, 35 (1990) 1913.

9 M.W. Breiter, Z. Physik. Chem. N.F., 112 (1978) 183.

10 A.R. Despic, D.M. Drazic, J. Balaksina, L. Gajic-Krstajic and R.M. Stevanovic, Electrochim. Acta, 35 (1990) 1747.

11 E. Wicke and G. Nernst, Ber. Bunsenges. Phys. Chem., 68 (1964) 224.

12 M.R.G. de Chialvo, M.F.L. de Mele, R.C. Salvarezza and A.J. Arvia, Corros. Sci., 28 (1988) 121.

13 G.J. Hills, D.J. Schiffrin and J. Thompson, Electrochim. Acta, 19 (1974) 657.

14 B. Scharifker and G.J. Hills, Electrochim. Acta, 28 (1983) 879. 